IZA DP No. 8353

Fast Times During Spring Breaks: Are Traffic Fatalities Another Consequence?

Michael T. French

Gulcin Gumus

July 2014 


\title{
Fast Times During Spring Breaks: Are Traffic Fatalities Another Consequence?
}

\author{
Michael T. French \\ University of Miami
}

Gulcin Gumus

Florida Atlantic University

and IZA

\author{
Discussion Paper No. 8353 \\ July 2014
}

IZA
P.O. Box 7240
53072 Bonn
Germany

\author{
Phone: +49-228-3894-0 \\ Fax: +49-228-3894-180 \\ E-mail: iza@iza.org
}

\begin{abstract}
Any opinions expressed here are those of the author(s) and not those of IZA. Research published in this series may include views on policy, but the institute itself takes no institutional policy positions. The IZA research network is committed to the IZA Guiding Principles of Research Integrity.

The Institute for the Study of Labor (IZA) in Bonn is a local and virtual international research center and a place of communication between science, politics and business. IZA is an independent nonprofit organization supported by Deutsche Post Foundation. The center is associated with the University of Bonn and offers a stimulating research environment through its international network, workshops and conferences, data service, project support, research visits and doctoral program. IZA engages in (i) original and internationally competitive research in all fields of labor economics, (ii) development of policy concepts, and (iii) dissemination of research results and concepts to the interested public.
\end{abstract}

IZA Discussion Papers often represent preliminary work and are circulated to encourage discussion. Citation of such a paper should account for its provisional character. A revised version may be available directly from the author. 


\section{ABSTRACT}

\section{Fast Times During Spring Breaks: Are Traffic Fatalities Another Consequence?*}

Every year in the United States, millions of college students travel for spring break, spending billions of dollars. We examine a potential adverse consequence of spring break that has received little attention in the literature - traffic safety. In particular, we estimate the impact of spring break season on fatal passenger vehicle crashes. Using daily county-level longitudinal data on traffic fatalities in popular spring break destinations from 1982-2011, we conduct separate analyses by age groups, license status, and alcohol involvement in the crash. Our findings indicate that passenger vehicle fatalities are significantly overrepresented during the spring break season.

JEL Classification: I12, I18, H73

Keywords: $\quad$ spring break, college students, traffic fatalities, externalities

Corresponding author:

Gulcin Gumus

Florida Atlantic University

Department of Management Programs

777 Glades Road

313 Fleming Hall

Boca Raton, FL 33431

USA

E-mail: ggumus@fau.edu

\footnotetext{
* Note: Authors are listed alphabetically. We gratefully acknowledge Tonja Lindsey at the National Center for Statistics and Analysis Office of Traffic Records and Analysis, National Highway Traffic Safety Administration, for her assistance with the FARS data. We are indebted to Brittany M. Harder, Emmanouil Mentzakis, Linnea A Polgreen, Lisa M. Powell, Daniel I. Rees, Nicholas Sando, and participants at the 9th World Congress of the International Health Economics Association, the 2013 Addiction Health Services Research Conference, the 6th IZA Annual Meeting on the Economics of Risky Behaviors, and the 5th Biennial Conference of the American Society of Health Economists for their constructive comments on earlier versions of the paper. We also thank Audry M. Klossner for excellent research assistance and Carmen Martinez for administrative support.
} 


\section{INTRODUCTION}

Between the end of February and the beginning of April, college students from all over the U.S. travel to warmer climates to enjoy a week off from classes. This "spring break" phenomenon dates back to the late 1930s when Florida, especially the city of Fort Lauderdale, became a travel hotspot among college students (Bohn, 2009). Since then, spring break (SB) has progressively turned into a college tradition, particularly for students in northern schools who take advantage of the appealing climate in Florida. Currently, SB travel encompasses virtually all college students to become a huge component of American college culture. It is estimated that every year millions of students travel for SB, spending billions of dollars on transportation, lodging, food, and entertainment (Ribeiro, 2011; Scott-Halsell and Saiprasert, 2011).

Since the 1930s, besides Florida, cities in California, Nevada, Texas, Mexico, and the Caribbean have become magnets for spring breakers (Bohn, 2009). Popular destinations receive significant economic benefits from increased tourism revenue and employment due to this travel phenomenon. However, these destinations also experience adverse impacts such as increased traffic crashes, public intoxication including driving under the influence (DUI), overcrowding, vandalism, littering, hospitalizations, and noise pollution (Laurie, 2008). As a result, local communities and public officials struggle to weigh the stimulus to the local economy against the unwanted harms and risky behaviors associated with the $\mathrm{SB}$ environment.

One of the most dangerous and avoidable consequences of SB is fatal and non-fatal traffic crashes, especially those caused by drunk driving. However, this adverse outcome has received almost no attention in the literature. To address this gap, we examine the impact of SB season on fatal passenger vehicle crashes. Specifically, we investigate whether traffic fatalities significantly increase during the weeks when college students arrive at SB hotspots in the U.S. We use daily 
county-level longitudinal data on passenger vehicle fatalities from the 1982-2011 Fatality Analysis

Reporting System (FARS). In addition to the aggregate analysis, we conduct separate analyses by age groups and by alcohol involvement in the crash. Using the extensive crash characteristics available in FARS, we also examine disaggregated fatality rates corresponding to in-state versus outof-state driver involvement. Our findings indicate that passenger vehicle fatalities are significantly overrepresented during the SB season.

\section{BACKGROUND}

College students, being mostly younger adults, are not only relatively inexperienced drivers, but are also challenged by driving in an unfamiliar environment if they travel far from home for their $\mathrm{SB}$ vacation. Moreover, drinking and driving is quite prevalent among this population. American College Health Association's (AHCA, 2013) National College Health Assessment reveals that, within the past 30 days, 23.9 percent of students reported driving after having any alcohol and 2.8 percent reported driving after consuming five or more drinks. As more colleges and universities establish campus policies to ban alcohol or restrict access, this can fuel the demand for heavy episodic drinking during SB. Some studies even report students selecting their vacation destinations in hopes of maximizing their ability to drink, such as underage American students vacationing in Mexico where the minimum legal drinking age is lower (Apostolopoulos et al., 2002).

Murphy et al. (2012, p.339) report that, compared to adult drinkers, "college students tend to drink episodically, in relatively large social groups, outside of the context of meals, and often in large quantities over short periods.” SB season may exacerbate these behaviors due to heightened impulsivity and greater peer pressure during such holidays. Many college students use SB as an opportunity to "let loose" and "party hard." Several studies provide empirical evidence that students on SB vacation partake in elevated levels of risky activities, especially when alcohol is 
involved. For example, Apostolopoulos and colleagues (2002) report that 49 percent of male and 38 percent of female college students report having sex as a direct outcome of excessive drinking on SB vacation. Moreover, they find that one third of the students they surveyed reported that they had sex with someone they first met on SB. These casual sexual encounters are particularly risky given that 75 percent of students reported never or rarely using a condom on SB (Apostolopoulos et al., 2002). Sönmez et al. (2006) confirm these findings and discover that students are significantly more likely to participate in riskier behaviors in the SB environment than when they stay at home.

More recently, Patrick and Lee (2012) find that students engage in more risky behaviors when they are vacationing with friends on SB. They report that students are more likely to have sex, consume more alcohol, achieve higher levels of blood alcohol concentration (BAC), and report more episodes of intoxication when they are on SB. Lee et al. (2006) show that students engage in relatively higher amounts of alcohol consumption during SB if they travel with friends and if they are members of fraternities or sororities. Similarly, Grekin et al. (2007) find that college students traveling together with friends tend to consume more alcohol whereas students who stayed home or traveled with their parents during SB were less likely to engage in excessive alcohol use.

Findings from the existing studies have significant public health and social welfare implications, and they also highlight the need for possible educational campaigns to protect students and others from serious consequences occurring during the SB season. One important and yet overlooked negative externality is traffic crashes in locations that receive a large amount of college students during the SB season. It has been established that motor vehicle deaths tend to increase during good weather and periods of increased recreational travel (e.g., Farmer and Williams, 2005). Studies have also shown that fatalities and injuries in traffic crashes are overrepresented during holidays due to increased risky driving behaviors on the roads (e.g., Anowar et al., 2013). However, 
to the best of our knowledge, there is no rigorous study examining the effects of SB season on traffic safety. Balkin and Ord (2001, p.11) report that Florida tends to have more fatal crashes in March and they speculate that this pattern could be due to "the increase of traffic from college students traveling to Florida on spring break." However, they do not formally investigate this issue and instead focus on how speed limit increases affect fatal interstate crashes.

\section{DATA AND EMPIRICAL METHODS}

The passenger vehicle fatality data used in this study come from the Fatality Analysis Reporting System (FARS). FARS is a publicly available data source on fatal vehicular crashes and is maintained by National Highway Traffic Safety Administration (NHTSA). Passenger vehicles include cars, vans, SUVs, and pickup trucks; motorcycles, scooters, large trucks, buses, off-road vehicles, etc. are excluded. Fatalities refer to both occupants (i.e. drivers and passengers) as well as non-occupants (e.g., pedestrians, bicyclists). We obtained daily fatality data from the 1982-2011 FARS, which were then aggregated to construct weekly fatality totals, where a week is a period of seven successive days from Sunday through Saturday. As part of robustness checks, we adopted various other definitions of a week as discussed below. The days of the year are not exactly divisible by seven, and so in some years days are left over before the first full week and/or after the last full week. Given that these "left-over days" are not comparable to full weeks, they are excluded from our analyses.

We obtained fatality data for 21 different areas: 14 popular SB counties and the states wherein these counties are located. These seven states are Arizona, California, Florida, Nevada, South Carolina, Texas, and Virginia. Commonly visited SB locations for college students also include Mexico and the Caribbean, but we focus only on domestic locations for which comparable fatality data are available. The 14 counties, together with the corresponding SB destination cities, are 
listed in Appendix A. Using these county- and state-level data, we construct fatality figures for the remaining combined non-spring-break counties in each of the seven SB states. This allows us to carry out a comparison between the SB counties and the "rest of the state."

To identify the most intensive weeks of SB season, we collected data on SB schedules for virtually all colleges and universities in the U.S. together with the corresponding enrollment data (see Appendix B). Unfortunately, information is not available on how many students travel during SB or their exact travel destinations. However, the enrollment data coupled with SB schedules clearly shows that the most intensive weeks of travel are the four weeks of March, which we consecutively denote by weeks 2-5. In addition, the SB shoulder weeks include the last week of February (week 1) and the first week of April (week 6). As part of a falsification test, we also define adjacent weeks: week 0 is the third week of February (i.e., the week before the SB season starts) and week 7 is the second week of April (i.e., the week following the end of the SB season).

As part of our analysis, we utilize extensive crash characteristics available in FARS to investigate whether the SB season has differential impacts for various fatality measures. Total fatalities refer to the number of passenger vehicle drivers and passengers killed in traffic crashes. The FARS database enables us to decompose total fatalities by license state. If the driver is licensed in the state where the crash occurred, we count the fatalities as in-state. In contrast, out-of-state fatalities occur in crashes that involve a driver who is licensed in a state other than that where the crash occurred. Next, we divide total fatalities into two groups according to the driver's BAC or the driver with the highest BAC if multiple drivers are involved: non-alcohol-impaired (BAC is under $0.08 \mathrm{~g} / \mathrm{dL}$ ) versus alcohol-impaired (BAC is $0.08 \mathrm{~g} / \mathrm{dL}$ or higher) fatalities. These BAC figures are either reported by law enforcement or imputed based on characteristics of the crash and driver (Adams et al., 2012; Subramanian, 2002). Finally, we break down fatalities by the driver's age group. 
We distinguish between fatalities in crashes that involve young drives (i.e. at least one driver is 25 years old or younger) versus those that did not involve any young drivers (i.e. all drivers are more than 25 years old).

A common approach in the traffic safety literature is to estimate fixed-effects linear regression models using fatality rates defined either as fatalities divided by population, vehicle registrations, or vehicle miles traveled. Given that we analyze weekly data and frequently observe zero fatalities in some counties, we estimate a conditional fixed-effects negative binomial model to account for overdispersion in fatality counts (Hausman et al., 1984). The estimation is by maximum likelihood and is conditional on the total weekly count of fatalities in each county. Specifically, we estimate the following equation:

$$
F_{i w t}=S B_{w} \beta+\delta_{i}+\lambda_{t}+\gamma T_{w}+\delta_{i} \times T_{w}+\varepsilon i w t
$$

where $\left(F_{i w t}\right)$ denotes the fatality count in area $i$, week $w$, and year $t$. Depending upon the specification, $(S B)$ is an indicator variable for either the entire six-week SB season or a vector of dummy variables indicating each of the six SB weeks. Area-specific fixed-effects, denoted by $\delta_{i}$, absorb time-invariant differences in passenger vehicle fatalities across counties and states. ${ }^{1} \lambda_{t}$ reflects the annual secular nationwide trends in traffic safety. In addition, we account for weekly linear time trends (within a given year), $\gamma T_{w}$, as well as area-specific weekly linear time trends, $\delta_{i} \times$ $T_{w}$. As a result, the estimated impact of $\mathrm{SB}$ on passenger vehicle safety is now identified by weekly within county/state deviations, net of the weekly area-specific time trends.

The coefficients of interest are contained in the $\beta$ vector. The direction, magnitude, and significance of the estimated coefficients indicate whether some or all of the SB weeks have an

\footnotetext{
${ }^{1}$ As demonstrated by Allison and Waterman (2002), the conditional fixed-effects negative binomial model is not a "true" fixed-effects method in the sense that it does not control for all non-time-varying covariates.
} 
intuitively predictable, statistically important, and practically meaningful effect on passenger vehicle safety. Given that we include area-specific time trends, which should account for much of the weekly variation in fatalities, the estimated effects can be interpreted as lower bounds of the true effect of SB. We also estimate the same specifications for the combined non-SB counties in each of the seven SB states in our sample. This provides a "difference-in-differences" type of comparison between the six-week SB season and the remaining 46 weeks across popular SB destinations versus the rest of the counties in those same seven states. Finally, we estimate specifications with supplemental indicators for weeks that are adjacent to the SB season (i.e., week 0 and week 7 ) as a falsification test. If the SB effects are strictly contained within the SB season, then we should find non-significant coefficient estimates for week 0 and week 7.

\section{RESULTS}

Table 1 provides descriptive statistics for the full sample, which includes weekly data for the 30 years from 1982 to 2011 . We separate the full sample into two groups: SB counties and the combined non-SB counties in SB states. The top panel in this table presents summary statistics for the SB counties. The average number of weekly fatalities in SB counties is 2.175 with a standard deviation (2.557) that is higher than the mean. The bottom panel reports descriptive statistics for the rest of the counties in those states that include at least one SB hotspot. The average fatality count in these seven SB states is 32.990 per week, which is obviously much higher compared to the county-level average. When we break down the fatality figures by driver characteristics, we see that fatalities in crashes involving drivers with in-state licenses, with no alcohol impairment $(\mathrm{BAC}<0.08)$, and no young drivers are far more common, and this pattern holds for both the top and bottom panels of Table 1.

[Insert Table 1 Here] 
In Table 2, we present a comparison of average weekly fatalities between SB weeks and the remaining weeks of the year. The top panel again corresponds to the SB counties where average weekly fatalities during SB weeks are higher compared to non-SB weeks. This is true not only for total fatalities, but also for all the other categories we consider. Except for fatalities of drivers with in-state licenses $(p<0.05)$, all the differences are statistically significant at the one percent level. The bottom panel reports the average weekly fatalities in the combined non-SB counties for SB states. In stark contrast to the top panel, average weekly fatalities are higher during non-SB weeks compared to SB weeks with one exception (drivers with out-of-state licenses). Some of these differences, however, are not statistically significant. Although these comparisons are a rather simple way of gauging the impact of the SB season on traffic fatalities, they provide an initial glimpse before we proceed with our regression analysis.

\section{[Insert Table 2 Here]}

\section{A. Main Estimates}

Tables 3-6 present estimation results for the conditional fixed-effects negative binomial models with the weekly count of passenger vehicle fatalities as the dependent variable. For the key explanatory variables, we report the estimated incidence rate ratios (IRR) and the corresponding standard errors (in parentheses). ${ }^{2}$ IRRs are the exponentiated coefficients and indicate the difference in fatalities predicted by the model when the variable of interest is increased by one unit above its mean value while all other variables are kept constant at their means (see Table 1 for the summary statistics). A value greater than one reflects a positive relationship between fatality counts and the particular regressor, while a value less than one suggests the opposite. Statistical significance is

\footnotetext{
${ }^{2}$ For brevity, we suppress the estimation results for county/state fixed-effects, year fixed-effects, linear weekly time trends, and area-specific time trends. These results can be obtained from the authors upon request.
} 
based on a test of the null hypothesis that there is no relationship between fatalities and the control variable (i.e., IRR is equal to one).

First, we consider the SB counties in columns 1-3 of Table 3. Column 1 includes a single dummy variable for the entire SB season (i.e., weeks 1-6). The estimated IRR in this column indicates that the weekly number of fatalities in SB counties is 9.1 percent higher during the SB season compared to the remaining weeks of the year $(p<0.01)$. This translates into about 0.2 additional traffic fatalities per week during the SB season in a given county, which yields more than 16 additional fatalities in our sample (i.e. all 14 counties) during the entire 6-week SB season in any given year $(2.175 \times 0.091=0.198$ fatalities per week and SB county, and $0.198 \times 14$ SB counties $=$ 2.771 , and $2.771 \times 6$ weeks $=16.626)$. In column 2 , we include separate dummy variables for each of the six weeks of the SB season. Estimated effects for these week-specific indicators vary between 6.5-13.2 percent. With the exception of week 1, all of the estimates are statistically significant. In column 3 of Table 3, we augment the model in column 2 with dummy variables for the two adjacent weeks (i.e., the week before the SB season starts and the week after the SB season ends). If the fatality effects are confined to the SB period, then the IRRs for these adjacent weeks should not be significantly different from one. As expected, the IRRs for the adjacent weeks (i.e., weeks 0 and 7 in Table 3) are close to one and non-significant. In addition, the inclusion of these two indicators leaves the estimated impact of the SB on fatalities virtually unchanged.

[Insert Table 3 Here]

In the last three columns of Table 3, we consider the other counties in SB states. The estimated IRR in the specification with a single dummy variable for the entire SB season (column 4) is 0.990 and non-significant. This suggests that $\mathrm{SB}$ season does not have a significant impact on traffic fatalities in non-SB counties located in SB states. When we include separate dummy variables 
for each SB week (column 5), almost none of the estimated IRRs are significantly different from one. The only exception is week 1 , but the estimated IRR is 0.963 , suggesting a 3.7 percent decrease in fatalities during this week $(\phi<0.05)$. The last column of Table 3 indicates that in non-SB counties, the week right before the SB season starts (i.e. week 0) is associated with 4.8 percent fewer fatalities $(p<0.05)$ while the other adjacent week (i.e. week 7) is associated with a 3.6 percent increase in fatalities $(p<0.10)$. While we are unable to posit definitive explanations for these adjacent-week findings, we speculate that it might be due to travel patterns associated with other (i.e., non-SB) vacationers during these weeks. Nevertheless, the absence of a significant increase in fatalities in non-SB counties during the SB season offers counterfactual evidence in support of a true SB effect in SB hotspots.

Comparing columns 1-3 with columns 4-6 in Table 3 reveals that the SB season is associated with higher fatalities in SB counties and this pattern is clearly different from what is observed in the other counties in SB states. ${ }^{3}$ It is important to note, however, that spring breakers often travel through other counties in a SB state and sometimes choose other destinations in those states even if they are not necessarily SB hotspots (e.g., counties on the west coast of Florida). As a result, comparing SB hotspots and the "rest of the state" is not always a clear distinction, so we view the estimated effects of SB on traffic fatalities as a lower bound to the true estimates.

In Table 4, we decompose total passenger vehicle fatalities according to the driver's license status (i.e. whether the driver is licensed in or out of the state where the crash occurred). If college students are challenged by driving in an unfamiliar environment as they travel far from home during their vacation, then we may see a greater effect on fatalities among out-of-state drivers during the SB

\footnotetext{
${ }^{3}$ We also estimated conditional fixed-effects Poisson models that allow for clustering at the area level. Although this exercise increased the standard errors somewhat, it did not meaningfully alter any of our conclusions and can be obtained from the authors upon request.
} 
season compared to in-state drivers. We consider fatalities of in-state drivers in columns 1 and 2 and out-of-state drivers in columns 3 and 4 . Even though both in-state and out-of-state fatalities are positively associated with the SB season in SB counties, the impact is much more pronounced for fatalities in crashes that involved out-of-state drivers. Specifically, only week 5 for SB counties is significantly related to in-state fatalities $(p<0.05)$ and none of the SB weeks are significantly associated with in-state fatalities for non-SB counties. On the other hand, as presented in column 3, the most popular weeks of the SB season (i.e., weeks 2-5) are significantly associated with a greater number of out-of-state fatalities in SB counties $(p<0.05)$. Moreover, the estimated IRRs are relatively large, ranging from 19.7 to 24.6 percent. Two of the estimated IRRs (for weeks 3 and 4) are statistically significant for out-of-state fatalities among non-SB counties (column 4), but the impact is more modest as both estimates are less than 10 percent. Thus, as expected, an influx of college students traveling to SB counties is contributing to a greater number of traffic fatalities overall, but especially among out-of-state drivers.

\section{[Insert Table 4 Here]}

Table 5 reports the results for fatalities broken down by the age of the driver and once again we compare the SB counties with the non-SB counties located in the SB states. The first two columns correspond to crashes that involved one or more young drivers (age 25 or younger) and the last two columns report estimates for crashes that did not involve any young drivers. In SB counties, four of the six SB weeks are associated with significantly higher fatality counts for crashes that involved a young driver(s) and the corresponding IRRs are quite high (11.3 to 20.4 percent). Only one of the IRRs is significantly different from one for other counties in SB states, but the direction is negative instead of positive. As for fatalities in crashes that involved no young drivers, 
the first two SB weeks have marginally significant positive effects. The last two columns reveal that a similar phenomenon does not appear to exist in non-SB counties in SB states.

\section{[Insert Table 5 Here]}

The last of our disaggregated analyses addresses the issue of alcohol involvement in traffic crashes by decomposing fatalities into two groups: non-alcohol-impaired $(\mathrm{BAC}<0.08)$ and alcoholimpaired (BAC $\geq 0.08)$. If spring breakers are drinking heavily during their vacation and then driving after partying, we would expect to see significantly more alcohol-impaired fatalities in SB counties during SB weeks. As shown in Table 6, both types of fatalities are typically higher during the SB season in SB counties whereas they are generally lower during this period in non-SB counties. However, lack of statistical significance does not allow us to draw any firm conclusions about alcohol involvement. ${ }^{4}$ One possible explanation is that spring breakers may be using safer forms of transportation (e.g., taxi, designated sober drivers) after consuming alcohol. Alternatively, they may be consuming alcohol in resorts or high-density beach communities where they stay, hence eliminating the need for transportation altogether.

\section{[Insert Table 6 Here]}

\section{B. Robustness}

To examine the stability of our core findings, we conducted several robustness checks. First, we implemented a falsification test to determine whether the SB season is atypical compared to other high-traffic periods. Research shows that traffic is heaviest during the weeks surrounding holiday periods. Independence Day ( $4^{\text {th }}$ of July), Labor Day (first Monday of September), Christmas Day ( $25^{\text {th }}$ of December), and New Year's Day ( $1^{\text {st }}$ of January) are the top four deadliest holidays in the U.S. in terms of passenger vehicle fatalities (Farmer and Williams, 2005). Thus, these weeks

\footnotetext{
${ }^{4}$ We also constructed fatality groups as non-alcohol-involved $(\mathrm{BAC}=0)$ and alcohol-involved $(\mathrm{BAC}>0)$. Again, this alternative grouping did not meaningfully alter the conclusions presented here.
} 
should exhibit significantly higher fatality counts compared to non-holiday periods, regardless of whether the analysis applies to SB counties or non-SB counties in SB states. In Table 7, we report the results of this falsification test. The fact that traffic fatalities spike during most of these holiday periods for both SB and non-SB counties offers face validity to our SB estimates. A comparison between columns 1 and 2 does not reveal any systematic differences in the direction or statistical significance of the IRR estimates between the SB counties and non-SB counties during these holiday periods. The same holds for the comparison between columns 3 and 4. If SB counties are inherently more dangerous throughout the year, then we should certainly see significant differences during these holidays compared to the rest of the state. The absence of any meaningful differences between SB and non-SB counties during these holidays suggests that our SB findings are indeed unique and robust.

\section{[Insert Table 7 Here]}

The core analyses for this study used total and disaggregated fatality counts. To provide an alternative comparison between popular SB destinations and the rest of the counties in the same states, we also estimated fixed-effects linear regression models using "adjusted" differences in passenger vehicle fatalities. This alternative dependent variable is defined as $\left(F_{S B}-F_{N S B}\right) / F_{S}$ where $F_{S B}, F_{N S B}$, and $F_{S}$ denote weekly fatality counts for a $\mathrm{SB}$ county in a given state, for the combined non-SB counties in the same state, and for the entire state (i.e. $F_{S}=F_{S B}+F_{N S B}$ ), respectively. Although extremely rare, this ratio is undefined (and thus treated as a missing observation) when zero fatalities occurred in the entire state for a particular week. After creating this adjusted dependent variable, we estimate linear fixed-effects models with the same set of regressors as in Equation (1) above. The corresponding results are presented in Tables 8 and 9. 
In Table 8, we focus on the adjusted differences in total fatalities. The estimate for the dummy variable associated with the six-week SB season (column 1) is positive and highly statistically significant $(\phi<0.01)$. This alternative specification indicates that, once again, during the SB season, fatalities in SB counties are significantly higher compared to fatalities in non-SB counties. Even though the estimates in Table 8 do not offer a quantitative interpretation as intuitive as the IRRs from the count models presented earlier, we believe this adjusted measure has the advantage of allowing us to directly gauge the differential effects of SB on traffic fatalities in SB counties (i.e., focusing on a single set of regression results rather than making side-by-side comparisons as in Tables 3-7). When including dummy variables for each of the six SB weeks (column 2), four of the coefficient estimates are positive and statistically significant $(p<0.05)$. Finally, as reported in column 3, the effects associated with the adjacent weeks are non-significant and the estimates for the SB weeks are unchanged.

\section{[Insert Table 8 Here]}

Table 9 provides a similar analysis to that in Table 8 for the decomposed fatality measures. While the SB season is associated with positive and statistically significant effects in SB counties for all the decomposed fatality measures, the effects are even more pronounced for the out-of-state and younger driver fatalities. Regardless of alcohol involvement, fatalities are higher in SB counties during the SB season (columns 5 and 6). However, empirical support for higher alcohol-impaired fatalities during SB is rather weak. Thus, vis-à-vis our core set of analyses, these findings provide additional empirical support for the differential effects of SB in SB counties. We also replicated the analysis in Table 7 using the adjusted differences in total passenger vehicle fatalities and these estimation results yield no statistically significant coefficients associated with the weeks surrounding Independence Day, Labor Day, Christmas Day, and New Year's Day. Again, this confirms that the 
patterns we uncover pertaining to the SB season are not detected for other holiday periods during which these travel hotspots may be receiving a significant number of visitors.

$$
\text { [Insert Table } 9 \text { Here] }
$$

Our final robustness check involved alternative definitions for the start and end of a SB week. The core analysis is based on a definition for a week that starts on Sunday and ends the following Saturday. Using the daily fatality data from FARS, we experimented with two alternative definitions of a week: one from Saturday through Friday and the other from Monday through Sunday. We then re-estimated all models using these alternative definitions. Regardless of how we defined a week, the estimation results are largely unchanged. These estimates are not presented in tables, but the full set of estimation results from these robustness checks can be obtained from the authors upon request.

\section{DISCUSSION AND FUTURE RESEARCH}

This study considers traffic fatalities as a potential adverse consequence of SB. Specifically, we examine whether and to what extent SB season has an impact on fatal passenger vehicle crashes in 14 popular SB destinations in the U.S. Our findings indicate that passenger vehicle fatalities are significantly higher in SB counties when comparing SB season to other weeks of the year and also when comparing SB counties to non-SB counties in the same states. This SB effect is more pronounced for out-of-state drivers (relative to in-state drivers) and younger drivers $(\leq 25$ years). Despite strong concerns about drunk driving during the SB season, our results reveal few differences between alcohol-impaired and non-alcohol-impaired fatalities during SB weeks. We also carry out various falsification and robustness checks that confirm these core results.

The analysis presented here has a few shortcomings that should be noted. First, given data limitations, we are unable to adjust passenger vehicle fatalities by vehicle miles traveled because such 
data are not available by county and week. Second, we are unable to control for the exact number of tourists (including spring breakers) in each county and week, so the models do not adjust for population density or tourism exposure. Third, we collected information on SB schedules for all colleges and universities across the U.S. to identify the most popular SB weeks, which formed the primary independent variables. These schedules coupled with student enrollments may be the best available information for determining the participation and intensity associated with SB travel, but it obviously does not fully capture the actual amount of SB visitors in each of the destinations. Fourth, stay-at-home spring breakers and those who travel abroad may also be contributing to adverse consequences in those locations, but we lack corresponding data to include them in our analysis. Lastly, while our analysis reveals an increased traffic death toll associated with SB season, it does not resolve the possible mechanisms. Increased passenger vehicle fatalities during SB could be due to a variety of reasons including more motor vehicles on the roads; a greater number of passengers per vehicle; a higher prevalence of impaired driving, inexperienced drivers, and speeding; reduced use of seat belts; and other factors. Perhaps future policy research could shed some light on these alternative explanations in order to assist policymakers as they consider educational programs and more aggressive police enforcement strategies targeting risky driving behaviors during $\mathrm{SB}$ season.

It should be noted that we are unable to distinguish between the traffic effects associated with an influx of tourists (both spring breakers and others) from those related to a higher prevalence of risky behavior and/or peer effects among spring breakers. However, existing literature presents compelling evidence that students are significantly more likely to participate in risky behaviors when they are in the SB environment with friends than when they stay at home (e.g., Grekin et al., 2007; Patrick and Lee, 2012; Sönmez et al., 2006). This suggests that SB seasons can indeed lead to 
increased traffic fatality rates overall, rather than just shifting students to certain destinations where more crashes occur due to increased population and congestion. More importantly, even if SB simply shifts students to where traffic crashes occur, instead of leading to more crashes, the strength and stability of our findings suggest a role for policy measures to address the fatal consequences associated with SB. Given the relatively small number of SB hotspots in the country where at-risk students are grouped together for only a few weeks each year, enforcement of traffic and alcohol policies at these destinations can be enhanced and intensified in an effort to save lives. As an example, for those counties that continue to host spring breakers, perhaps local officials can improve traffic safety during the SB season by providing free taxi and/or public transportation vouchers to students with a valid college ID.

After becoming an iconic SB destination during the last quarter of the $20^{\text {th }}$ century, the city of Fort Lauderdale adopted stricter public drinking laws, banned sleeping in cars as well as parking overnight at the beach, and publicly announced that college students are no longer welcome (Briggs, 2008). For many other SB destinations across the country, however, such policies may not be feasible given the substantial economic benefits they receive from spring breakers. A full economic evaluation associated with hosting spring breakers is outside the scope of the present study, but this may be a fruitful area for future research. Nevertheless, our findings contribute new information to the spirited policy debates on SB restrictions as host communities investigate whether the economic benefits generated by SB visitors outweigh various adverse consequences they create, including traffic fatalities. Moreover, college students might reflect on these findings as they plan future SB itineraries. Perhaps college administrators and parents will also consider these results as they try to improve student safety during SB travels. 


\section{REFERENCES}

Adams, S., M.L. Blackburn, and C.D. Cotti. "Minimum Wages and Alcohol-Related Traffic Fatalities among Teens.” Review of Economics and Statistics, 94(3), 2012, 828-840.

Allison, P.D., and R.P. Waterman. "Fixed-Effects Negative Binomial Regression Models." Sociological Methodology, 32(1), 2002, 247-265.

American College Health Association (AHCA). National College Health Assessment II: Reference Group Data Report Fall 2012. Hanover, MD: American College Health Association, 2013.

Anowar, S., S. Yasmin, and R. Tay. "Comparison of crashes during public holidays and regular weekends." Accident Analysis and Prevention, 51, 2013, 93-97.

Apostolopoulos, Y., S. Sönmez, and C.H. Yu. "HIV-risk behaviours of American spring break vacationers: a case of situational disinhibition?" International Journal of STD \& AIDS, 13(11), 2002, 733-743.

Balkin, S., and J.K. Ord. "Assessing the Impact of Speed-Limit Increases on Fatal Interstate Crashes." Journal of Transportation and Statistics, 4(1), 2001, 1-26.

Bohn, L. "A brief history of spring break," Time Magazine, March 30, 2009, accessed June 16, 2013, http:/ /www.time.com/time/ nation/article/0,8599,1888317,00.html.

Briggs, B. "Florida towns send spring break crowd abroad: Fort Lauderdale shows how to transform image by turning away business," NBC News, March 17, 2008, accessed June 16, 2013, http://www.nbcnews.com/id/23565992/ns/business-us_business/t/florida-towns-send-springbreak-crowd-abroad.

Farmer, C.M., and A.F. Williams. "Temporal factors in motor vehicle crash deaths." Injury Prevention, 11(1), 2005, 18-23. 
Grekin, E.R., K.J. Sher, and J.L. Krull. "College spring break and alcohol use: Effects of spring break activity." Journal Studies on Alcohol and Drugs, 68(5), 2007, 681-688.

Hausman, J.A., B.H. Hall, and Z. Griliches. "Econometric models for count data with an application to the patents-R\&D relationship." Econometrica, 52 (4), 1984, 909-938.

Hobson, J.S.P., and B. Josiam. "Spring break student travel: a longitudinal study." Journal of V acation Marketing, 2(2), 1996, 137-150.

Laurie, J. "Spring Break: The Economic, Socio-Cultural and Public Governance Impacts of College Students on Spring Break Host Locations.” Paper 876, University of New Orleans Theses and Dissertations, 2008.

Lee, C.M., J.L. Maggs, and L.A. Rankin. “Spring Break Trips as a Risk Factor for Heavy Alcohol Use Among First-Year College Students.” Journal of Studies on Alcohol, 67(6), 2006, 911-916.

Mcleod, R. “A brief history of spring break,” Rolling Stone, April 2, 1998, Issue 783, 56-61.

Murphy, J.G., N.P. Barnett, and C.J. Correia. "Future Directions in College Student Alcohol Abuse Research and Prevention." In College Student Alcohol Abuse: A Guide to Assessment, Intervention, and Prevention, edited by C.J. Correia, J.G. Murphy, and N.P. Barnett, 339-347. Hoboken, NJ: John Wiley \& Sons, Inc., 2012.

Patrick, M.E., and C.M. Lee. "Daily variations in spring break alcohol and sexual behaviors based on intentions, perceived norms, and daily trip context." Journal of Studies on Alcohol and Drugs, 73(4), 2012, 591-596.

Ribeiro, N.F.C.C.D. "Culture, consensus and behavior among North-American spring breakers," unpublished dissertation, Pennsylvania State University, 2011.

Scott-Halsell, S.A. and W. Saiprasert. "Spring Break: Pulling in the Student Market." Journal of Tourism Insights, 2(2), 2011, Article 3. 
Sönmez, S., Y. Apostolopoulos, C.H. Yu, S. Yang, A. Mattila, and L.C. Yu. "Binge Drinking and Casual Sex on Spring-Break." Annals of Tourism Research, 33(4), 2006, 895-917.

Subramanian, R. NHTS A Technical report: Transitioning to Multiple Imputation - A New Method to Estimate Missing Blood Alcohol Concentration (BAC) in FARS. DOT HS 809 403. Washington, DC: Department of Transportation, 2002. 


\section{APPENDIX A}

The list of popular spring break (SB) destinations was compiled based on existing literature reviews conducted by Laurie (2008) and Ribeiro (2011) as well as other historical reviews including Hobson and Josiam (1996) and Mcleod (1998). We also gathered information from various SB travel websites such as the MTV Spring Break Timeline: http://www.time.com/time/ nation/article/0,8599,1888317,00.html (accessed June 16, 2013).

$\begin{array}{lll}\text { City } & \text { County } & \text { State } \\ \text { Lake Havasu City } & \text { Mohave County } & \text { Arizona } \\ \text { Palm Springs } & \text { Riverside County } & \text { California } \\ \text { San Diego } & \text { San Diego County } & \text { California } \\ \text { Panama City Beach } & \text { Bay County } & \text { Florida } \\ \text { Fort Lauderdale } & \text { Broward County } & \text { Florida } \\ \text { Fort Myers Beach } & \text { Lee County } & \text { Florida } \\ \text { South Miami Beach and Miami } & \text { Miami-Dade County } & \text { Florida } \\ \text { Key West } & \text { Monroe County } & \text { Florida } \\ \text { Daytona Beach } & \text { Volusia County } & \text { Florida } \\ \text { Las Vegas } & \text { Clark County } & \text { Nevada } \\ \text { Myrtle Beach } & \text { Horry County } & \text { South Carolina } \\ \text { South Padre Island } & \text { Cameron County } & \text { Texas } \\ \text { Austin } & \text { Travis County } & \text { Texas } \\ \text { Virginia Beach } & & \text { Virgina }\end{array}$




\section{APPENDIX B}

Spring break weeks together with the corresponding student population figures are as follows:

$\underline{\text { Weeks }}$

Week 1 (last week of February)

Week 2 (first week of March)

Week 3 (second week of March)

Week 4 (third week of March)

Week 5 (last week of March)

Week 6 (first week of April)

TOTAL

\section{$\underline{\text { Student Population }}$}

181,357

707,904

$2,658,760$

$1,845,916$

946,270

237,113

$6,577,320$

\section{$\underline{\text { Percent }}$}

3

11

40

28

14

4

100

This information was obtained from:

http://www.tripsmarter.com/travelinfo/panama-city-beach/spring-break-college-university-dates (accessed June 16, 2013). 
TABLE 1

Descriptive statistics, $1982-2011^{\mathrm{a}}$

\begin{tabular}{|c|c|c|c|c|}
\hline & Mean & Std. Dev. & Min & $\operatorname{Max}$ \\
\hline \multicolumn{5}{|l|}{ Spring break counties $(N=21,840)$} \\
\hline Total passenger vehicle fatalities & 2.175 & 2.557 & 0.000 & 21.000 \\
\hline \multicolumn{5}{|l|}{ Fatalities in crashes involving: } \\
\hline drivers with in-state licenses & 1.734 & 2.206 & 0.000 & 16.000 \\
\hline drivers with out-of-state licenses & 0.440 & 0.868 & 0.000 & 10.000 \\
\hline drivers with $\mathrm{BAC}<0.08^{\mathrm{b}}$ & 1.443 & 1.887 & 0.000 & 15.000 \\
\hline drivers with $\mathrm{BAC} \geq 0.08^{\mathrm{b}}$ & 0.748 & 1.157 & 0.000 & 12.000 \\
\hline young drivers (age $\leq 25$ ) & 0.883 & 1.348 & 0.000 & 14.000 \\
\hline no young drivers (age $>25$ ) & 1.292 & 1.708 & 0.000 & 14.000 \\
\hline \multicolumn{5}{|c|}{ Combined non-spring-break counties for spring break states $(N=10,920)$} \\
\hline Total passenger vehicle fatalities & 32.990 & 25.921 & 0.000 & 139.000 \\
\hline \multicolumn{5}{|l|}{ Fatalities in crashes involving: } \\
\hline drivers with in-state licenses & 27.370 & 22.927 & 0.000 & 128.000 \\
\hline drivers with out-of-state licenses & 5.620 & 4.233 & 0.000 & 32.000 \\
\hline drivers with $\mathrm{BAC}<0.08^{\mathrm{b}}$ & 20.774 & 16.348 & 0.000 & 84.000 \\
\hline drivers with $\mathrm{BAC} \geq 0.08^{\mathrm{b}}$ & 12.068 & 10.921 & 0.000 & 60.000 \\
\hline young drivers (age $\leq 25)$ & 13.350 & 11.687 & 0.000 & 70.000 \\
\hline no young drivers (age $>25$ ) & 19.640 & 15.295 & 0.000 & 75.000 \\
\hline
\end{tabular}

Notes: ${ }^{a}$ Observations are weekly for each spring break (SB) county and for the combined non-SB counties in states that have at least one SB county. As a result, there are 21,840 observations for SB counties (52 weeks x 30 years $x 14$ counties) and 10,920 observations for SB states (52 weeks x 30 years x 7 states). ${ }^{b} \mathrm{BAC}$ is the blood alcohol content of the driver.

Source: Authors' own calculations using FARS data. 
TABLE 2

Average weekly fatalities for spring break (SB) season versus rest of the year, 1982-2011

\begin{tabular}{|c|c|c|c|c|}
\hline & \multicolumn{4}{|c|}{ Spring break counties } \\
\hline & SB season & Rest of the year & Difference & $p$-value \\
\hline & (1) & (2) & $(1)-(2)$ & $(1)-(2)$ \\
\hline Total passenger vehicle fatalities & 2.313 & 2.157 & 0.157 & 0.004 \\
\hline \multicolumn{5}{|l|}{ Fatalities in crashes involving: } \\
\hline drivers with in-state licenses & 1.784 & 1.728 & 0.056 & 0.233 \\
\hline drivers with out-of-state licenses & 0.530 & 0.429 & 0.101 & 0.000 \\
\hline young drivers (age $\leq 25)$ & 1.538 & 1.430 & 0.108 & 0.007 \\
\hline no young drivers (age $>25$ ) & 0.785 & 0.744 & 0.042 & 0.089 \\
\hline drivers with $\mathrm{BAC}<0.08^{\mathrm{b}}$ & 0.961 & 0.873 & 0.088 & 0.002 \\
\hline drivers with $\mathrm{BAC} \geq 0.08^{\mathrm{b}}$ & 1.353 & 1.284 & 0.069 & 0.057 \\
\hline \multirow[t]{4}{*}{$\mathrm{N}=21,840$} & 2,520 & 19,320 & & \\
\hline & \multicolumn{4}{|c|}{ Combined non-spring-break counties for spring break states } \\
\hline & SB season & Rest of the year & Difference & $p$-value \\
\hline & $(1)$ & $(2)$ & $(1)-(2)$ & $(1)-(2)$ \\
\hline Total passenger vehicle fatalities & 31.690 & 33.160 & -1.470 & 0.058 \\
\hline \multicolumn{5}{|l|}{ Fatalities in crashes involving: } \\
\hline drivers with in-state licenses & 26.025 & 27.545 & -1.521 & 0.027 \\
\hline drivers with out-of-state licenses & 5.665 & 5.614 & 0.051 & 0.690 \\
\hline young drivers (age $\leq 25$ ) & 19.865 & 20.893 & -1.027 & 0.036 \\
\hline no young drivers (age $>25$ ) & 11.710 & 12.114 & -0.405 & 0.216 \\
\hline drivers with $\mathrm{BAC}<0.08^{\mathrm{b}}$ & 12.875 & 13.412 & -0.537 & 0.125 \\
\hline drivers with $\mathrm{BAC} \geq 0.08^{\mathrm{b}}$ & 18.814 & 19.747 & -0.933 & 0.042 \\
\hline $\mathrm{N}=10,920$ & 1,260 & 9,660 & & \\
\hline
\end{tabular}

Notes: ${ }^{a}$ Observations are weekly for each spring break (SB) county and for the combined non-SB counties in states that have at least one SB county. ${ }^{\mathrm{b}} \mathrm{BAC}$ is the blood alcohol content of the driver.

Source: Authors' own calculations using FARS data. 
TABLE 3

Total passenger vehicle fatalities, conditional fixed-effects negative binomial models

\begin{tabular}{|c|c|c|c|c|c|c|}
\hline & \multicolumn{3}{|c|}{ SB counties } & \multicolumn{3}{|c|}{ Combined non-SB counties for SB states } \\
\hline & (1) & (2) & (3) & (4) & (5) & (6) \\
\hline SB season (weeks 1-6) & $\begin{array}{c}1.091 * * * \\
(0.022)\end{array}$ & & & $\begin{array}{c}0.990 \\
(0.008)\end{array}$ & & \\
\hline Week 1 & & $\begin{array}{c}1.065 \\
(0.047)\end{array}$ & $\begin{array}{c}1.063 \\
(0.047)\end{array}$ & & $\begin{array}{c}0.963 * * \\
(0.018)\end{array}$ & $\begin{array}{c}0.962 * * \\
(0.018)\end{array}$ \\
\hline Week 2 & & $\begin{array}{c}1.098 * * \\
(0.047)\end{array}$ & $\begin{array}{c}1.097 * * \\
(0.047)\end{array}$ & & $\begin{array}{c}0.993 \\
(0.018)\end{array}$ & $\begin{array}{c}0.992 \\
(0.019)\end{array}$ \\
\hline Week 3 & & $\begin{array}{c}1.089 * * \\
(0.047)\end{array}$ & $\begin{array}{c}1.088^{*} \\
(0.047)\end{array}$ & & $\begin{array}{c}1.003 \\
(0.018)\end{array}$ & $\begin{array}{c}1.002 \\
(0.019)\end{array}$ \\
\hline Week 4 & & $\begin{array}{c}1.083^{*} \\
(0.047)\end{array}$ & $\begin{array}{c}1.082^{*} \\
(0.047)\end{array}$ & & $\begin{array}{c}0.983 \\
(0.018)\end{array}$ & $\begin{array}{c}0.981 \\
(0.018)\end{array}$ \\
\hline Week 5 & & $\begin{array}{c}1.132^{* * *} \\
(0.048)\end{array}$ & $\begin{array}{c}1.131^{* * *} \\
(0.048)\end{array}$ & & $\begin{array}{c}0.981 \\
(0.018)\end{array}$ & $\begin{array}{c}0.980 \\
(0.018)\end{array}$ \\
\hline Week 6 & & $\begin{array}{c}1.077 * \\
(0.046)\end{array}$ & $\begin{array}{l}1.076^{*} \\
(0.046)\end{array}$ & & $\begin{array}{c}1.015 \\
(0.018)\end{array}$ & $\begin{array}{c}1.014 \\
(0.018)\end{array}$ \\
\hline Week 0 & & & $\begin{array}{c}0.950 \\
(0.044)\end{array}$ & & & $\begin{array}{c}0.952^{* *} \\
(0.018)\end{array}$ \\
\hline Week 7 & & & $\begin{array}{c}1.039 \\
(0.046)\end{array}$ & & & $\begin{array}{l}1.036^{*} \\
(0.019)\end{array}$ \\
\hline Log-likelihood & $-36,576.80$ & $-36,576.17$ & $-36,575.10$ & $-35,590.61$ & $-35,587.96$ & $-35,582.45$ \\
\hline $\mathrm{N}$ & 21,840 & 21,840 & 21,840 & 10,920 & 10,920 & 10,920 \\
\hline
\end{tabular}

Notes: Observations are weekly for each spring break (SB) county and for the combined non-SB counties in states that have at least one SB county. As a result, there are 21,840 observations for SB counties (52 weeks x 30 years x 14 counties) and 10,920 observations for SB states (52 weeks x 30 years $\mathrm{x} 7$ states). Each model includes county/state and year fixed effects, a linear time trend, and area-specific time trends. For each explanatory variable, we report the estimated incidence rate ratios (IRR) and the standard errors in parentheses. Statistical significance is based on the test of the hypothesis that IRR $=1 . *, * *, * * *$ Significant at the 10, 5, and 1 percent level, respectively.

Source: Authors' own calculations using FARS data. 
TABLE 4

Passenger vehicle fatalities by license status, conditional fixed-effects negative binomial models

\begin{tabular}{|c|c|c|c|c|}
\hline & \multicolumn{2}{|c|}{ In-state } & \multicolumn{2}{|c|}{ Out-of-state } \\
\hline & SB counties & $\begin{array}{c}\text { Combined non-SB } \\
\text { counties for SB states }\end{array}$ & SB counties & $\begin{array}{c}\text { Combined non-SB } \\
\text { counties for SB states }\end{array}$ \\
\hline & (1) & (2) & (3) & (4) \\
\hline Week 1 & $\begin{array}{c}1.078 \\
(0.051)\end{array}$ & $\begin{array}{c}0.970 \\
(0.019)\end{array}$ & $\begin{array}{c}1.080 \\
(0.092)\end{array}$ & $\begin{array}{l}0.933 * \\
(0.037)\end{array}$ \\
\hline Week 2 & $\begin{array}{l}1.053 \\
(0.050)\end{array}$ & $\begin{array}{c}0.987 \\
(0.019)\end{array}$ & $\begin{array}{c}1.230^{* * * *} \\
(0.099)\end{array}$ & $\begin{array}{l}1.023 \\
(0.039)\end{array}$ \\
\hline Week 3 & $\begin{array}{l}1.026 \\
(0.050)\end{array}$ & $\begin{array}{c}0.984 \\
(0.019)\end{array}$ & $\begin{array}{c}1.246^{* * *} \\
(0.099)\end{array}$ & $\begin{array}{l}1.082^{* *} \\
(0.040)\end{array}$ \\
\hline Week 4 & $\begin{array}{c}1.042 \\
(0.050)\end{array}$ & $\begin{array}{c}0.968 \\
(0.019)\end{array}$ & $\begin{array}{c}1.230^{* * * *} \\
(0.097)\end{array}$ & $\begin{array}{l}1.071 * \\
(0.040)\end{array}$ \\
\hline Week 5 & $\begin{array}{l}1.102 * * \\
(0.051)\end{array}$ & $\begin{array}{c}0.971 \\
(0.019)\end{array}$ & $\begin{array}{c}1.197 * * \\
(0.095)\end{array}$ & $\begin{array}{l}1.023 \\
(0.039)\end{array}$ \\
\hline Week 6 & $\begin{array}{l}1.056 \\
(0.050)\end{array}$ & $\begin{array}{c}1.003 \\
(0.019)\end{array}$ & $\begin{array}{c}1.139 \\
(0.093)\end{array}$ & $\begin{array}{l}1.057 \\
(0.039)\end{array}$ \\
\hline Log-likelihood & $-32,624.87$ & $-33,466.51$ & $-17,567.84$ & $-25,544.91$ \\
\hline $\mathrm{N}$ & 21,840 & 10,920 & 21,840 & 10,920 \\
\hline
\end{tabular}

Notes: Observations are weekly for each spring break (SB) county and for the combined non-SB counties in states that have at least one SB county. As a result, there are 21,840 observations for SB counties (52 weeks x 30 years x 14 counties) and 10,920 observations for SB states (52 weeks x 30 years $\times 7$ states). Each model includes county/state and year fixed effects, a linear time trend, and area-specific time trends. For each explanatory variable, we report the incidence rate ratios (IRR) and the standard errors in parentheses. Statistical significance is based on the test of the hypothesis that IRR $=1$. *,**,*** Significant at the 10,5 , and 1 percent level, respectively.

Source: Authors' own calculations using FARS data.

TABLE 5

Passenger vehicle fatalities by driver's age, conditional fixed-effects negative binomial models

\begin{tabular}{|c|c|c|c|c|}
\hline & \multicolumn{2}{|c|}{ Young drivers (age $\leq 25$ ) } & \multicolumn{2}{|c|}{ No young drivers (age $>25$ ) } \\
\hline & SB counties & $\begin{array}{l}\text { Combined non-SB } \\
\text { counties for SB states }\end{array}$ & SB counties & $\begin{array}{c}\text { Combined non-SB } \\
\text { counties for SB states }\end{array}$ \\
\hline & (1) & (2) & (3) & (4) \\
\hline \multirow[t]{2}{*}{ Week 1} & 1.061 & $0.943^{* *}$ & $1.092 *$ & 0.977 \\
\hline & $(0.068)$ & $(0.026)$ & $(0.057)$ & $(0.021)$ \\
\hline \multirow[t]{2}{*}{ Week 2} & 1.093 & 0.998 & $1.091 *$ & 0.994 \\
\hline & $(0.069)$ & $(0.027)$ & $(0.056)$ & $(0.021)$ \\
\hline \multirow[t]{2}{*}{ Week 3} & $1.162^{* *}$ & 0.997 & 1.015 & 1.009 \\
\hline & $(0.071)$ & $(0.027)$ & $(0.054)$ & $(0.021)$ \\
\hline \multirow[t]{2}{*}{ Week 4} & $1.113^{*}$ & 1.008 & 1.049 & 0.969 \\
\hline & $(0.069)$ & $(0.027)$ & $(0.055)$ & $(0.021)$ \\
\hline \multirow[t]{2}{*}{ Week 5} & $1.204^{* * *}$ & 1.019 & 1.062 & $0.956^{* *}$ \\
\hline & $(0.072)$ & $(0.027)$ & $(0.055)$ & $(0.021)$ \\
\hline \multirow[t]{2}{*}{ Week 6} & $1.184 * * *$ & 1.023 & 0.996 & 1.010 \\
\hline & $(0.071)$ & $(0.027)$ & $(0.053)$ & $(0.021)$ \\
\hline Log-likelihood & $-24,847.53$ & $-29,254.77$ & $-29,235.83$ & $-31,865.03$ \\
\hline $\mathrm{N}$ & 21,840 & 10,920 & 21,840 & 10,920 \\
\hline
\end{tabular}

Notes: Observations are weekly for each spring break (SB) county and for the combined non-SB counties in states that have at least one SB county. As a result, there are 21,840 observations for SB counties (52 weeks x 30 years x 14 counties) and 10,920 observations for SB states (52 weeks x 30 years x 7 states). Each model includes county/state and year fixed effects, a linear time trend, and area-specific time trends. For each explanatory variable, we report the estimated incidence rate ratios (IRR) and the standard errors in parentheses. Statistical significance is based on the test of the hypothesis that IRR $=1 . *, * *, * *$ Significant at the 10, 5, and 1 percent level, respectively.

Source: Authors' own calculations using FARS data. 
TABLE 6

Passenger vehicle fatalities by driver's BAC, conditional fixed-effects negative binomial model results

\begin{tabular}{|c|c|c|c|c|}
\hline & \multicolumn{2}{|c|}{ Non-alcohol-impaired $(\mathrm{BAC}<0.08)$} & \multicolumn{2}{|c|}{ Alcohol-impaired (BAC $\geq 0.08)$} \\
\hline & SB counties & $\begin{array}{l}\text { Combined non-SB } \\
\text { counties for SB states }\end{array}$ & SB counties & $\begin{array}{l}\text { Combined non-SB } \\
\text { counties for SB states }\end{array}$ \\
\hline & (1) & $(2)$ & (3) & (4) \\
\hline Week 1 & $\begin{array}{l}1.105^{* *} \\
(0.055)\end{array}$ & $\begin{array}{c}0.944 * * * \\
(0.020)\end{array}$ & $\begin{array}{c}0.975 \\
(0.066)\end{array}$ & $\begin{array}{c}1.001 \\
(0.027)\end{array}$ \\
\hline Week 2 & $\begin{array}{c}1.061 \\
(0.053)\end{array}$ & $\begin{array}{c}1.010 \\
(0.020)\end{array}$ & $\begin{array}{l}1.135^{* *} \\
(0.072)\end{array}$ & $\begin{array}{c}0.970 \\
(0.027)\end{array}$ \\
\hline Week 3 & $\begin{array}{l}1.091 * \\
(0.054)\end{array}$ & $\begin{array}{c}1.009 \\
(0.020)\end{array}$ & $\begin{array}{c}1.048 \\
(0.068)\end{array}$ & $\begin{array}{c}0.999 \\
(0.027)\end{array}$ \\
\hline Week 4 & $\begin{array}{c}1.079 \\
(0.053)\end{array}$ & $\begin{array}{c}0.987 \\
(0.020)\end{array}$ & $\begin{array}{c}1.051 \\
(0.069)\end{array}$ & $\begin{array}{c}0.987 \\
(0.027)\end{array}$ \\
\hline Week 5 & $\begin{array}{l}1.103^{* *} \\
(0.054)\end{array}$ & $\begin{array}{c}0.978 \\
(0.020)\end{array}$ & $\begin{array}{l}1.130^{*} \\
(0.071)\end{array}$ & $\begin{array}{c}0.988 \\
(0.027)\end{array}$ \\
\hline Week 6 & $\begin{array}{c}1.070 \\
(0.053)\end{array}$ & $\begin{array}{c}1.017 \\
(0.020)\end{array}$ & $\begin{array}{c}1.042 \\
(0.068)\end{array}$ & $\begin{array}{c}1.017 \\
(0.027)\end{array}$ \\
\hline Log-likelihood & $-30,204.04$ & $-31,721.28$ & $-23,153.61$ & $-28,448.21$ \\
\hline $\mathrm{N}$ & 21,840 & 10,920 & 21,840 & 10,920 \\
\hline
\end{tabular}

Notes: Observations are weekly for each spring break (SB) county and for the combined non-SB counties in states that have at least one SB county. As a result, there are 21,840 observations for SB counties (52 weeks x 30 years x 14 counties) and 10,920 observations for SB states (52 weeks $\times 30$ years $\times 7$ states). BAC is the blood alcohol content of the driver. Each model includes county/state and year fixed effects, a linear time trend, and area-specific time trends. For each explanatory variable, we report the estimated incidence rate ratios (IRR) and the standard errors in parentheses. Statistical significance is based on the test of the hypothesis that IRR $=1 . *, * *, * * *$ Significant at the 10, 5, and 1 percent level, respectively.

Source: Authors' own calculations using FARS data.

TABLE 7

Falsification test using holiday periods, conditional fixed-effects negative binomial model results

\begin{tabular}{lcccc}
\hline \hline & SB counties & $\begin{array}{c}\text { Combined non-SB } \\
\text { counties for SB states }\end{array}$ & SB counties & $\begin{array}{c}\text { Combined non-SB } \\
\text { counties for SB states }\end{array}$ \\
Independence Day period & $(1)$ & $(2)$ & $(3)$ & $1.093^{* * *}$ \\
Labor Day period & $1.089^{* *}$ & $1.094^{* * *}$ & $1.101^{* *}$ & $(0.019)$ \\
& $(0.046)$ & $(0.019)$ & $(0.047)$ & $1.032^{* *}$ \\
Christmas Day period & 1.032 & $1.032^{* *}$ & 1.036 & $(0.013)$ \\
New Year's Day period & $(0.032)$ & $(0.013)$ & $(0.033)$ & 0.973 \\
& 1.011 & 0.972 & 1.003 & $(0.018)$ \\
SB season (weeks 1-6) & $(0.045)$ & $(0.018)$ & $(0.045)$ & 0.974 \\
& 0.955 & 0.976 & 0.985 & $(0.048)$ \\
Log-likelihood & $(0.114)$ & $(0.048)$ & $(0.117)$ & 0.993 \\
N & - & - & $1.094 * * *$ & $(0.008)$ \\
& & & $(0.022)$ & $-35,573.38$ \\
\hline
\end{tabular}

Notes: Holiday periods correspond to the week that contains each holiday. Observations are weekly for each spring break (SB) county and for the combined non-SB counties in states that have at least one SB county. As a result, there are 21,840 observations for SB counties (52 weeks x 30 years x 14 counties) and 10,920 observations for SB states (52 weeks x 30 years $\mathrm{x} 7$ states). Each model includes county/state and year fixed effects, a linear time trend, and area-specific time trends. For each explanatory variable, we report the estimated incidence rate ratios (IRR) and the standard errors in parentheses. Statistical significance is based on the test of the hypothesis that IRR $=1 . *, * *, * * *$ Significant at the 10,5 , and 1 percent level, respectively.

Source: Authors' own calculations using FARS data. 
TABLE 8

Adjusted differences in total passenger vehicle fatalities, linear fixed-effects regression models

Week 1

Week 2

Week 3

Week 4

Week 5

Week 6

Week 0

Week 7

Mean of the dep. variable

St. Dev. of the dep. variable

Log-likelihood

$\mathrm{N}$

Notes: Dependent variable is defined as the total fatalities in a given spring break (SB) county minus the total fatalities for the combined non-SB counties in the corresponding state that includes the specific SB county, and these differences are then adjusted by the total fatalities in the entire state (including both the SB and non-SB county figures). Observations are weekly for each spring break (SB) county. As a result, there are a total of 21,840 observations (52 weeks x 30 years $\times 14$ counties). The missing observations are due to zeros in the denominator of the adjusted differences measure, i.e. zero total fatalities in the entire state in a given week. Each model includes county/state and year fixed effects, a linear time trend, and area-specific time trends. *, **, *** Significant at the 10, 5 , and 1 percent level, respectively.

Source: Authors' own calculations using FARS data.
(1)

\begin{abstract}
$0.015^{* * *}$
\end{abstract}
$(0.005)$

(3)

(2)

$\begin{array}{cc}0.030^{* *} & 0.030^{* *} \\ (0.011) & (0.012) \\ 0.017^{* *} & 0.018^{* *} \\ (0.008) & (0.008) \\ 0.011^{* *} & 0.011^{* *} \\ (0.004) & (0.005) \\ -0.003 & -0.003 \\ (0.008) & (0.008) \\ 0.022^{* *} & 0.022^{* *} \\ (0.008) & (0.009) \\ 0.014 & 0.014 \\ (0.009) & (0.010) \\ - & 0.001 \\ & (0.007) \\ - & 0.005 \\ & (0.008)\end{array}$

$-0.76$

0.302

$8,862.19$

21,824
$8,867.19$

$8,867.39$
21,824 
TABLE 9

Adjusted differences in passenger vehicle fatalities by license status, driver's age, and driver's BAC, linear fixed-effects regression models

\begin{tabular}{|c|c|c|c|c|c|c|}
\hline & In-state & Out-of-state & $\begin{array}{c}\text { Young drivers } \\
(\text { age } \leq 25)\end{array}$ & $\begin{array}{c}\text { No young drivers } \\
(\text { age }>25)\end{array}$ & $\begin{array}{c}\text { Non-alcohol-impaired } \\
\text { BAC }<0.08\end{array}$ & $\begin{array}{c}\text { Alcohol-impaired } \\
\text { BAC } \geq 0.08\end{array}$ \\
\hline & (1) & (2) & (3) & (4) & (5) & (6) \\
\hline SB season (weeks 1-6) & $\begin{array}{l}0.013^{* *} \\
(0.005)\end{array}$ & $\begin{array}{l}0.026^{* * *} \\
(0.009)\end{array}$ & $\begin{array}{l}0.021^{* * *} \\
(0.006)\end{array}$ & $\begin{array}{c}0.013^{*} \\
(0.006)\end{array}$ & $\begin{array}{l}0.013^{* * *} \\
(0.003)\end{array}$ & $\begin{array}{c}0.018^{*} \\
(0.008)\end{array}$ \\
\hline Mean of the dep. variable & -0.765 & -0.769 & -0.770 & -0.772 & -0.764 & -0.775 \\
\hline St. Dev. of the dep. variable & 0.336 & 0.352 & 0.340 & 0.314 & 0.320 & 0.339 \\
\hline Log-likelihood & $5,807.59$ & $-3,849.96$ & $1,163.49$ & $4,217.73$ & $4,984.77$ & 463.73 \\
\hline $\mathrm{N}$ & 21,757 & 21,407 & 21,524 & 21,768 & 21,765 & 21,568 \\
\hline
\end{tabular}

Notes: Dependent variable in each column is defined as the fatalities in a given spring break (SB) county minus the fatalities for the combined non-SB counties in the corresponding state that includes the specific SB county, and these differences are then adjusted by the fatalities in the entire state (including both the SB and non-SB county figures). Observations are weekly for each spring break (SB) county. As a result, there are a total of 21,840 observations (52 weeks x 30 years x 14 counties). The missing observations are due to zeros in the denominator of the adjusted differences measure, i.e. zero fatalities in the entire state for any given measure. BAC is the blood alcohol content of the driver. Each model includes county/state and year fixed effects, a linear time trend, and area-specific time trends. *, **, *** Significant at the 10,5 , and 1 percent level, respectively.

Source: Authors' own calculations using FARS data. 